\title{
O cooperativismo habitacional e a gestão coletiva da propriedade como garantia da segurança da posse de populações vulnerabilizadas: o community Land Trust
}

\author{
Habitational cooperativism and collective property management as a guarantee of \\ security of the possession of vulnerable populations? the community Land Trust
}

\begin{abstract}
Resumo
0 "Community Land Trust" é um modelo estabelecido com vistas à proteção de permanência de comunidades vulnerabilizadas em territórios. A figura surge nos EUA, na década de 60, atrelada aos movimentos por direitos civis e à população residente em áreas rurais. 0 presente artigo buscará avaliar as potencialidades e os limites da aplicação do instrumento do "Community Land Trust" no Brasil a partir de uma abordagem qualitativa e se utilizando da análise do conteúdo bibliográfico e documental existente sobre o tema. 0 instrumento do CLT, por exigir uma gestão coletiva territorial, incorpora no cooperativismo habitacional elementos e práticas contemporâneas de autogestão se mostrando o modelo que melhor representa valores como a ajuda mútua, democracia, igualdade e solidariedade e cuja utilização se adequa às necessidades de populações vulnerabilizadas.
\end{abstract}

Palavras-chave: Cooperativismo. community Land Trusts. segurança na posse. Autogestão e sustentabilidade.

\begin{abstract}
Community Land Trusts is an established model to protect the permanence of vulnerable communities in territories. The figure comes in the United States in the 1960s, tied to civil rights movements and the population living in rural areas. This article will evaluate the potential and limits of the application of the Community Land Trust instrument in Brazil from a qualitative approach and using the analysis of existing bibliographic and documentary content on the topic. The CLT instrument, as it requires collective territorial management, incorporates contemporary self-management elements and practices in housing cooperatives, showing itself to be the model that best represents values such as mutual aid, democracy, equality and solidarity and whose use is adapted to the needs of vulnerable populations.
\end{abstract}

Keywords: Cooperativism. Community Land Trust. security in possession. self-management and sustainability.

Renata Cristina Nascimento Antão ${ }^{\mathrm{I}}$, Tarcyla Fidalgo Ribeiro ${ }^{\mathrm{II}}$

I Universidade Federal do Rio de Janeiro. renata.antao@gmail.com

II Universidade Federal do Rio de Janeiro. tarcylafidalgo@gmail.com 


\section{Introdução}

A moradia adequada é um direito humano universal ${ }^{1}$ e precisa ser uma preocupação central quando tratamos de políticas urbanas. Apesar de todos os avanços legislativos obtidos a partir da Constituição Federal de 1988, a garantia da segurança da posse de populações vulneráveis segue como um desafio de grande vulto no país.

O tema tem tamanha importância que o objetivo no 11 dos Objetivos de Desenvolvimento Sustentável (ODS) é de "Cidades e Comunidades Sustentáveis", sendo a meta 11.1. a de "até 2030, garantir o acesso de todos a habitação segura, adequada e a preço acessível, e aos serviços básicos e urbanizar as favelas" (Agenda 2030, ONU)2.

A autogestão ou gestão coletiva em si merece destaque, estando presente em outros arranjos de propriedade espalhados em diversos países do mundo, como veremos ao longo do artigo, e constituindo uma importante base de resistência ao crescente movimento de mercantilização e financeirização ${ }^{3}$ da terra em detrimento do direito de seus moradores.

A América Latina é um celeiro de experiências de gestão coletiva territorial consuetudinárias ou modernas ${ }^{4}$, que merecem ser conhecidas e estudadas, como os Ejidos no México, as Comunidades nativas e campesinas com titulação coletiva no Peru, os Quilombos no Caribe e Brasil e as Cooperativas habitacionais no Uruguai. O cooperativismo, enquanto uma experiência mais contemporânea de autogestão é um dos modelos que melhor representa valores como a ajuda mútua, democracia, igualdade e solidariedade, o que levou a Organização das Nações Unidas (ONU) lançar em 31 de outubro de 2011 o Ano Internacional das Cooperativas e, em 2012, realizar esforços para expandir a consciência pública sobre o papel das cooperativas no cumprimento de Metas de Desenvolvimento do Milénio (ODM) como a redução da pobreza e o desenvolvimento socioeconômico5.

Neste sentido, se revela particularmente interessante a busca por instrumentos de regularização e sustentabilidade já aplicados e bem sucedidos em outros países, como é o caso do Community Land Trust, sendo possível afirmar que o Community Land Trust é, antes de qualquer outra definição de caráter mais técnico, um instrumento de garantia de segurança da posse para populações vulneráveis.

Trata-se de mecanismo difundido pelo mundo e de resultados amplamente satisfatórios não apenas no incremento da segurança da posse de populações vulneráveis, mas também da mobilização e emancipação dos moradores no que se refere à definição dos rumos de seu território e promoção de melhorias. Isto se dá, especialmente, pelos arranjos de gestão coletiva que são necessariamente desenhados para a aplicação deste modelo ${ }^{6}$.

\footnotetext{
${ }^{1}$ São diversos os diplomas legais que elevam o direito à moradia adequada à direito humano universal na legislação internacional, como a Declaração Universal dos Direitos Humanos de 1948, o Pacto Internacional de Direitos Econômicos, Sociais e Culturais de 1966., mas principalmente a Constituição brasileira em seu artigo 6o.

${ }^{2}$ Centro de Informação das Nações Unidas para o Brasil (UNIC Rio), última edição em 13 de outubro de 2015. Acesse este documento em inglês em http://bit.ly/2030agenda

${ }^{3} \mathrm{O}$ conceito financerização, embora relativamente recente é cada vez mais utilizado para descrever o modelo capitalista atual, apontando a existência de agentes e lógicas financeiras em sua relação com ativos como a terra (KLINK; SOUZA, 2017).

${ }^{4}$ Throughout Latin America and the Caribbean, lands are also held in common by maroon communities, descendants from Africans who had escaped from slavery in the Americas to mix with the Amerindians. Remaining maroon communities today are especially to be found in Jamaica, Suriname, Puerto Rico, Haiti, Dominican Republic, Cuba, and Brazil. Due to their isolation from colonists, these communities were able to preserve African traditions around shared land use, language, music, culture and religion. Their identities, however, have been threatened by assimilation into national populations often by taking their right to the lands and resources away" (ALGOED, 2018).

${ }^{5}$ Fonte: https://nacoesunidas.org/agencias-da-onu-lancam-ano-internacional-das-cooperativas-2012/

${ }^{6}$ Experiências exitosas de Community land trust podem ser vistas em diversos países como Estados Unidos, Canadá, Inglaterra, entre outros países, sendo a experiência do Cao falar dos megaprojetos urbanos e dos processos año Martin Peña, em Porto Rico a que mais nos interessa em razão de ter se dado em área de proteção ambiental ocupada por moradias de baixa renda.
} 
Tendo conhecimento desta diversidade de experiências latino americanas, o presente artigo pretende focar nas possibilidades e limites de um modelo de Community Land Trust no Brasil para o incremento da segurança da posse de populações vulneráveis e consequente garantia de cidades e comunidades sustentáveis, mas também como reforço de iniciativas de gestão coletiva territorial já existentes em nosso território como as cooperativas habitacionais. Para tanto o artigo buscará analisar experiências cooperativistas e/ou autogestionadas de outros países, analisar o instrumento do Community land trust em sua aplicação internacional para então propor um piloto de modelo que busque responder à demanda existente por proteção e sustentabilidade de populações vulneráveis.

Para isso o presente artigo se utilizará da pesquisa bibliográfica (material empírico documental) e para a partir da análise das experiências autogestionárias, comunitaristas e cooperativistas internacionais estabelecer possíveis bases de um modelo brasileiro de community land trust.

\section{A insegurança da posse de populações vulneráveis}

No Brasil, embora a precariedade da moradia popular tenha alta visibilidade material e simbólica, não existem informações precisas quanto a sua quantificação ou localização, tampouco existem dados precisos e confiáveis acerca da precariedade da posse para grupos sociais vulneráveis 7 . É notório, no entanto, que o país padece de um grave cenário de irregularidade fundiária, acompanhada de insegurança da posse especialmente no que se refere a populações vulneráveis, sempre sob ameaça de remoções, estatais ou mercadológicas, de seu território.

As políticas públicas brasileiras relacionadas ao desenvolvimento urbano sempre tiveram como traço uma ambiguidade quanto à postura do poder público, que alterna a repressão de políticas remocionistas, muitas vezes violentas, com tolerância e práticas clientelistas de intervenção urbana em áreas habitadas por populações vulneráveis.

No âmbito jurídico, com a promulgação da Constituição da República Federativa do Brasil de 1988 e seu capítulo que trata da política de desenvolvimento urbano (Art. 182 e 183 da CRFB/88), cujo objetivo é o de ordenar o pleno desenvolvimento das funções sociais da cidade e garantir o bemestar de seus habitantes, vê o aumento significativo do número de instrumentos e legislações progressistas no Brasil.

Essas trazem instrumentos urbanísticos que se pretendiam capazes de promover a democratização das cidades, como as Zonas Especiais de Interesse Social (ZEIS), as obrigações de parcelamento, edificação ou utilização compulsória que recaem sobre proprietários de imóveis urbanos não edificados, ou mesmo a desapropriação para fins de reforma urbana.

Ocorre que essas legislações e instrumentos não foram capazes de promover a segurança na posse das populações vulneráveis na prática, uma vez que dentre os diversos instrumentos promotores da função social da cidade, os mais utilizados foram aqueles que puderam ser utilizados de modo a favorecer interesses do capital imobiliário, como as Operações Urbanas, a Transferência do Direito de Construir, entre outros ${ }^{8}$.

Atualmente o processo de exclusão e a insegurança se agudiza, uma vez que as recentes mudanças regulatórias e espaciais ocorridas nas cidades brasileiras se instituíram no sentido de privilegiar a atuação de atores financeiros, bem como de garantir a criação de infraestruturas necessárias para as novas atividades do capitalismo, especialmente as financeiras. As cidades vêm,

\footnotetext{
${ }^{7}$ Conforme respostas da Permanent Mission of Brazil to the United Nations Office and other International Organizations in Geneva feitas ao Questionário sobre "Segurança da Posse", apresentado pela Relatora Especial sobre Moradia Adequada, Raquel Rolnik.

${ }^{8}$ Dentre as pesquisas que avaliam a baixa aplicação dos instrumentos urbanísticos voltados à promoção da função social da cidade podemos citar a pesquisa "Parcelamento, edificação ou utilização compulsórios e IPTU progressivo no tempo: regulamentação e aplicação", realizada em 2014 no âmbito do Programa Pensando o Direito, da extinta Secretaria de Assuntos Legislativos do Ministério da Justiça, que contou também com apoio do também extinto Ministério das Cidades.
} 
cada vez mais, cumprindo um papel de ajuste espaço-temporal (HARVEY, 2015) para as situações de sobreacumulação típicas do capitalismo, se colocando como espaço privilegiado de alocação de recursos, sob uma lógica de absorção de capitais e garantia de lucros elevados. Tal fato leva a uma compreensão da gestão urbana como uma espécie de empresariamento, no qual cabe a cada cidade se colocar como o produto mais interessante a fim de atrair capitais.

A dinâmica de empresariamento urbano (HARVEY, 2005) e de transformação das cidades conforme as necessidades recentes de um capitalismo que atua sob dominância financeira (GUTTMAN, 2008). A visão do empresariamento urbano e da cidade mercadoria (VAINER, 2000) e sua gestão comprometida eminentemente com interesses econômicos, deixa de lado os direitos da população e o ideário de cidades mais justas e solidárias, de modo que a cidade mercadoria tem na legislação excludente seu instrumental de manutenção e reprodução, uma vez que, a partir da produção legislativa, a modificação do espaço urbano é facilitada com o uso de instrumentos jurídicos como operações urbanas consorciadas, solo criado ou outorgas onerosas do direito de construir.

Produção normativa e neoliberalismo tanto caminham junto que podemos ver o avanço de pautas conservadoras, as urgentes e rápidas reformas de direitos e alterações legislativas percebidas após o golpe parlamentar. Dentre a legislação produzida neste cenário de aprofundamento neoliberal, podemos trazer a nova lei de regularização fundiária, 13.465/17, que modifica substancialmente o modelo de gestão fundiária nacional.

Sem a intenção de abordar de forma mais completa as alterações efetivadas pela nova lei, desejamos destacar aqui a questão da mudança de "modelo" da regularização fundiária e seus possíveis impactos para as cidades.

A regularização fundiária no Brasil apenas teve uma primeira sistematização em nível nacional em 2009, com o capítulo III da Lei 11.977/09, que regula o programa habitacional "Minha Casa, Minha Vida". Esta lei trazia um modelo de regularização fundiária de caráter amplo, no qual eram considerados os aspectos dominial, registral, urbanístico e social de assentamentos irregulares, no sentido de promoção da segurança da posse e garantia de direitos a seus moradores.

No entanto, com apenas 08 anos de vigência (o que é muito pouco se considerarmos a necessidade de capilarização desta legislação federal para mais de 5.200 municípios), e poucos meses após a subida ao poder do governo ilegítimo de Michel Temer, o referido capítulo legislativo foi inteiramente revogado pela Medida Provisória 759, posteriormente convertida na Lei 13.465/17, que se tornou o novo marco normativo nacional sobre o tema da regularização fundiária.

Este novo marco deixa de lado o aspecto plural do modelo de regularização anterior, fazendo opção clara pela regularização dominial e registral. Ou seja, deixam se ser exigidas medidas de urbanização e de assistência social, por exemplo, para se permitir chamar de regularização fundiária medidas apenas de distribuição de títulos para os moradores. Neste contexto, também não se deve perder de vista que a nova Lei privilegia a titulação pela propriedade privada plena, desprestigiando outras formas de aquisição de domínio como as concessões de uso.

Este modelo, que pretende então disseminar, por meio de política pública, a propriedade privada plena e individual no Brasil, se revela perigoso para as populações urbanas vulneráveis. Isto porque a propriedade privada não se mostra como instrumento suficientemente adequado para a garantia da segurança da posse destas populações, uma vez que favorece expulsões mercadológicas, especialmente em assentamentos localizados em áreas já valorizadas das cidades (caso das favelas situadas na zona sul carioca, por exemplo).

Nesse processo podemos perceber a intencionalidade de abrir espaço para os interesses de frações capitalistas à custa dos direitos dos moradores e das sociabilidades presentes no território.

Em pouco mais de um ano de ruptura democrática muitos dos avanços que estavam sendo construídos desde antes da constituinte de 1988 foram rapidamente esvaziados e mitigados e a reforma urbana tão vislumbrada nunca chegou a se concretizar e se distancia cada vez mais das 
possibilidades e objetivos da atual agenda política do governo brasileiro. Junto com a reforma urbana, outros direitos defendidos pelos movimentos de moradia também se veem esvaziados na atual conjuntura. A segurança na posse é componente central do direito à moradia adequada, de modo que sua ausência facilita remoções forçadas e expõe os grupos mais vulneráveis ao risco de várias violações dos direitos humanos. Daí a importância de buscar formas de incrementá-la e garanti-la, visto que os instrumentos presentes em nosso ordenamento jurídico não têm se mostrado suficientes para sua proteção adequada.

\section{Formas de gestão coletiva da propriedade no Brasil e no exterior}

A história da humanidade se forjou com lutas e resistências ao redor dos usos e apropriações do solo, sendo a disseminação social da propriedade privada uma imposição capitalista, na contramão da lógica natural e histórica de diversos povos e comunidades tradicionais e campesinas. A ideação de formas coletivas de gestão de terras é antiga e existem diversas formas costumeiras de ocupação e de uso de terras comunais, as quais podem ser vistas principalmente em sistemas consuetudinários de propriedade como o das comunidades indígenas e povos tradicionais ${ }^{9}$, mas também em formas contemporâneas de propriedade coletiva da terra, principalmente aquelas ligadas às comunidades agrícolas e coletivos de trabalho autogestionado.

Essas terras coletivas vão receber os mais variados nomes e formatos, como os ejidos no México, que são propriedades rurais de uso coletivo que tem origem no Império Asteca e modernamente se estabelecem quando o governo toma terras particulares e as disponibiliza para o uso comum, sendo incorporadas pelo sistema mexicano de encomiendas (abolido na Constituição de 1917) e, posteriormente, restauradas às aldeias sem terra em forma de concessões. A forma organizativa dos ejidos com assembleias comunitárias que acontecem a cada seis meses e estruturas internas de decisões coletivas, como os Conselhos Ejidais e os Conselhos de Vigilância possibilitam que os camponeses façam a gestão do território de acordo com suas demandas e necessidades.

"Chamamos propriedade social. E tem outras que são as propriedades comunitárias, comunais, que são as comunidades dos povos indígenas. Essa estrutura de ejido, que é de propriedade coletiva, abarca mais da metade do território nacional. Entre as 200 milhões de hectares, pelo menos 107 milhões estão nas mãos dos pequenos camponeses. Essa é uma herança da Revolução Mexicana. Possuímos uma base jurídica muito diferente a outros países. Essa é uma vantagem comparativa, de uma estrutura que funciona a nosso favor" (O Vermelho, 2018).

Podemos também mencionar a Terra Comunitária de Origem (TCO), reconhecida pelo Estado boliviano, uma vez que os direitos das nações e povos indígenas originários campesinos estão dispostos na Constituição Política do Estado (CPE) de 7 de fevereiro de 2009. A carta constitucional traz um modelo de Estado intercultural, plurinacional e comunitário com autonomias territoriais. Como forma de garantir essas autonomias territoriais a propriedade coletiva é prevista junto com a propriedade individual ${ }^{10}$ e o Estado reconhece e garante a propriedade comunitária ou coletiva compreendida nos territórios indígenas e de povos originários, comunidades interculturais e campesinas ${ }^{11}$.

\footnotetext{
${ }^{9}$ In Latin America Indigenous Peoples and local communities formally own or control 23 percent of land area on indigenous lands or community lands. Through major land reforms in the 20th century communities became legitimate landowners in 14 countries: as farming collectives (Chile, Peru, El Salvador, Nicaragua, Mexico), land associations (Honduras), peasant lands (Bolivia, Peru), and state cooperatives (Cuba). Political reforms also resulted in Indigenous Peoples acknowledged as collective landowners of traditional territories, embedded in new Constitutions in 13 countries: Panama, Peru, Chile, Guatemala, Nicaragua, Brazil, Colombia, Paraguay, Argentina, Bolivia, Ecuador, Venezuela and Mexico (Alden Wiley 2018: 7). ${ }^{10}$ DERECHO A LA PROPIEDAD

Artículo 56.

I. Toda persona tiene derecho a la propiedad privada individual o colectiva, siempre que ésta cumpla una función social.]II. Se garantiza la propiedad privada siempre que el uso que se haga de ella no sea perjudicial al interés colectivo.

III. Se garantiza el derecho a la sucesión hereditaria.

Acesso em 20 de novembro de 2018 - https://www.oas.org/dil/esp/Constitucion_Bolivia.pdf

${ }^{11}$ CAPÍTULO NOVENO
} 
Podemos ainda mencionar as terras coletivas na Venezuela, onde a propriedade coletiva é prevista nos artigos 37 a 39 do Decreto Ley № 8.198/2011, “Ley especial de regularización integral de la tenencia de la tierra de los asentamientos urbanos y periurbanos"12 segundo a qual o regime de propriedade coletiva será constituído através de ato jurídico-formal no qual a comunidade solicita a outorga coletiva da titularidade do terreno. Esta titularidade coletiva é exercida via Comités de Tierra Urbana, responsáveis pela gestão da propriedade.

Vemos, a partir das experiências brevemente indicadas acima, que diversos formatos coletivos de gestão do solo são encontrados na América Latina, muitos deles relacionados com a origem indígena e de sociedades comunitaristas, mas igualmente com as resistências campesinas e agrícolas.

Dentre as formas contemporâneas de posse coletiva de terras são diversas as iniciativas de uso alternativo à propriedade privada individual e de tentativa de garantir a função social da terra. Na América Latina, encontramos as cooperativas de terra (sendo o grande exemplo o do Uruguai), os Community Land Trusts (que existem em Porto Rico) e as formas coletivas de obtenção de propriedade como a usucapião coletiva brasileira.

O cooperativismo uruguaio data dos anos 60, quando a Ley Nacional de Vivienda (Lei no 13.728 de 17 de dezembro de 1968) deu forma jurídica ao "direito de uso e gozo", ou propriedade coletiva como chamam os cooperativistas uruguaios. Este modelo ganhou robustez com a Ley General de Cooperativas (Lei no 18.407, de 24 de outubro de 2008), que unificou as leis sobre o cooperativismo, regulamentando o cooperativismo habitacional em uma espécie de marco legal da legislação de habitação de caráter social.

A lei geral de cooperativas dispõe sobre os princípios do cooperativismo, trazendo uma nova modalidade ao modelo cooperativista com a figura das cooperativas de usuários, na qual o regime de adjudicação de habitação, ou seja, a possibilidade de transferência dessa propriedade às cooperativas, transforma a mentalidade proprietária do beneficiário de habitação de interesse social, uma vez que desindividualiza a propriedade. São várias as inovações trazidas pelo marco legislativo uruguaio, no sentido de garantir que "a habitação não será objeto de especulação imobiliária, nem para beneficiar, nem para prejudicar o cooperativista" (NAHOUM, 2013, p.46). A Ley General de Cooperativas não apenas traz princípios do cooperativismo, mas possibilita a adjudicação da habitação em uso e gozo ao cooperativado (RAFFO, 2014). Isto porque, enquanto os cooperativados possuem o direito de uso e gozo, a propriedade é da cooperativa.

\section{TIERRA Y TERRITORIO}

Artículo 394.

El Estado reconoce, protege y garantiza la propiedad comunitaria o colectiva, que comprende el territorio indígena originario campesino, las comunidades interculturales originarias y de las comunidades campesinas. La propiedad colectiva se declara indivisible, imprescriptible, inembargable, inalienable e irreversible y no está sujeta al pago de impuestos a la propiedad agraria. Las comunidades podrán ser tituladas reconociendo la complementariedad entre derechos colectivos e individuales respetando la unidad territorial con identidad.

Acesso em 20 de novembro de 2018 - https://www.oas.org/dil/esp/Constitucion_Bolivia.pdf

${ }^{12}$ Propiedad colectiva

Artículo 36. Se regula la tenencia de la tierra por usucapión o adjudicación de la propiedad colectiva de manera parcial o total en el lote de terreno ocupado por el asentamiento urbano popular y delimitado por su poligonal e igualmente en parcelas colindantes dentro del mismo.

Régimen de propiedad colectiva

Artículo 37. La constitución del régimen de propiedad colectiva es el acto jurídico formal mediante el cual una comunidad, que así lo decida en asamblea de ciudadanos y ciudadanas, acuerda solicitar el otorgamiento de la titularidad colectiva del lote total del terreno que ocupa, con el objeto de garantizar la permanencia física de su asentamiento urbano popular y el mejor aprovechamiento de su hábitat, en el que sus habitantes tienen el derecho exclusivo de uso, aprovechamiento y disfrute.

Organizaciones para adquirir la propiedad

Artículo 38. Los propietarios y propietarias de las bienhechurías que ocupan un mismo lote de terreno, por encontrarse en una edificación de varios niveles o en construcciones horizontales o en edificaciones mixtas que manifiesten su voluntad de obtener la propiedad colectiva, podrán constituirse en Comités de Tierra Urbana. El uso de estos terrenos será exclusivamente residencial, permitiéndose actividades productivas familiares.

Acesso em 20/11/2018 - https://www.ecolex.org/details/legislation/decreto-ley-no-819811-ley-especial-de-regularizacionintegral-de-la-tenencia-de-la-tierra-de-los-asentamientos-urbanos-y-periurbanos-lex-faoc102677/ 
O Modelo da Federación Uruguaya de Cooperativas de Vivienda por Ayuda Mutua (FUCVAM) é um modelo de produção habitacional que tem como elemento central a propriedade coletiva das habitações. 0 estatuto de cada cooperativa regula de forma integral a sua administração, com base em princípios do cooperativismo e, ao estabelecer a posse da habitação pelo cooperativado e a propriedade pela cooperativa, acaba criando um sistema coletivo com muitas vantagens para a segurança da posse e a garantia do direito de moradia no âmbito dos programas de habitação de interesse social. Hoje há mais de trinta mil famílias que integram as cooperativas de usuário no Uruguai, tanto de ajuda mútua ${ }^{13}$ quanto de poupança prévia ${ }^{14}$, e podemos dizer que o modelo vem resistindo por mais de quarenta anos às investidas do mercado imobiliário.

Por sua vez, o modelo de Community Land Trust, instituído inicialmente nos Estados Unidos, na década de 60, e hoje disseminado por vários lugares do mundo, tem como características a (i) autonomia de ingresso; a (ii) divisão entre propriedade do terreno e das construções; (iii) gestão coletiva; (iv) sustentabilidade visando à manutenção dos moradores em seus territórios de origem ainda que em cenários de ameaça por agentes externos/de mercado. Desta forma, o instrumento apresenta um potencial emancipatório em termos de utilização do instituto do direito de propriedade. Isto porque, sem romper com sua característica individual e privada, institui arranjo inovador em termos de gestão coletiva e de sustentabilidade para a manutenção da segurança da posse de populações vulneráveis, o que será melhor explanado ao fazermos suas interlocuções com a possibilidade de um propriedade coletiva na realidade jurídica brasileira.

Por fim, temos a experiência cooperativista no Brasil. A principal legislação a tratar de cooperativa habitacional no país é a Lei no 5.764, de 1971, que define a Política Nacional de Cooperativismo, institui o regime jurídico das sociedades cooperativas, e dá outras providências. Em novembro de 1999 foi promulgada a Lei $\mathrm{n}^{\circ}$ 9.867, que institui no Brasil a figura das cooperativas sociais, formadas majoritariamente por pessoas com desvantagem de acesso ao mundo do trabalho, porém seu uso é reduzido a poucas atividades e trabalhadores.

Diferentemente do que ocorreu com o cooperativismo de trabalho e de crédito, que em poucos anos estabeleceu marcos normativos mais sólidos e adequados ao trabalho realizado, o cooperativismo habitacional não possui um marco regulatório consolidado, tendo este se constituído em importante demanda de parte do movimento de moradia.Tais modelos, mais do que tentativas de encarar a propriedade da terra em outros formatos, trazem outros valores e usos a esta propriedade, sendo a autogestão um dos mais preciosos. 0 termo "autogestão pode ser utilizado para definir tanto a gestão coletiva de um bem ou unidade produtiva, quanto uma forma de gestão social não mercantilizada, na busca por alternativas à organização monetária e mercantil da moradia. Essa administração feita pelos participantes, comunheiros, membros de um grupo, é realizada em regime de democracia direta no que se refere à tomada de decisões.

\section{O cooperativismo no Brasil: Um recente olhar para a gestão coletiva habitacional}

Sobre cooperativismo no Brasil, foi realizada em 2012 pesquisa pelo Núcleo de Extensão em Economia Solidária da Universidade de São Paulo (NESOL/USP) e a Universidade Federal de Paraíba (INCUBES/PRAC/UFPB) sobre o "Regime Jurídico das Cooperativas Populares e Empreendimentos em Economia Solidária”. A pesquisa não apenas identificou os sujeitos sociais envolvidos no debate sobre cooperativismo, mas explorou os projetos de regulamentação do cooperativismo em tramitação no Congresso Nacional e os principais pontos controversos quanto a tributação, formas societárias e registro (KRUPPA, 2012). A principal legislação a tratar de cooperativa habitacional é a Lei no 5.764,

\footnotetext{
${ }^{13}$ Cooperativas de ajuda mútua são aquelas nas quais o consumo da habitação somente será alcançado pela cooperação da capacidade produtiva dos seus associados, ou seja, com a ajuda de todos.

14 As cooperativas de habitação de poupança prévia ("cooperativas de vivienda por ahorro previo") são aquelas cuja contrapartida ao financiamento pelo fundo habitacional é uma poupança previamente formada pelos membros cooperados. As cooperativas que operam através da ajuda mútua de seus associados são entidades complementares às cooperativas poupança prévia pois a ajuda mútua é tratada pela lei uruguaia como "um investimento não monetarizado que cumpre o papel de contrapartida ao financiamento para as famílias cuja renda é suficiente apenas para amortizar uma dívida de longo prazo, mas não para formar uma poupança antes de obter uma moradia" (BARAVELLI, 2006, p.64).
} 
de 1971, que define a Política Nacional de Cooperativismo, institui o regime jurídico das sociedades cooperativas, e dá outras providências. Em novembro de 1999 foi promulgada a Lei $\mathrm{n}^{\circ}$ 9.867, que institui no Brasil a figura das cooperativas sociais, formadas majoritariamente por pessoas com desvantagem de acesso ao mundo do trabalho, porém seu uso é reduzido a poucas atividades e trabalhadores.

Diferentemente do que ocorreu com o cooperativismo de trabalho e de crédito, que em poucos anos estabeleceu marcos normativos mais sólidos e adequados ao trabalho realizado, o cooperativismo habitacional não possui um marco regulatório consolidado, demanda antiga dos movimentos de moradia.

No cenário internacional, a existência e regulamentação de cooperativas voltadas para a construção e gestão de moradias de interesse social é mais antiga e desenvolvida que no caso brasileiro, onde os programas de habitação de interesse social foram pautados pela lógica proprietária e o direito à casa própria ${ }^{15}$. Um dos fatores principais para esta realidade é a estrutura de financiamento dos programas Crédito Solidário e Minha Casa Minha Vida para produção por autogestão, que vinculam a questão dominial ao financiamento, impedindo arranjos de natureza mais emancipatória a partir da autogestão, para além da autoconstrução.

As cooperativas habitacionais para fins de garantia de direitos como a moradia e a cidade têm potencial, ainda pouco explorado no Brasil, o qual depende do incremento da segurança jurídica na atuação do cooperativismo habitacional.

\section{O Termo territorial coletivo e suas potencialidades para no Brasil}

A tradução do termo Community Land Trust para a língua portuguesa é controversa e envolve mais do que a busca por palavras cujo significado seja mais próximo dos termos trazidos pela língua inglesa. Dada sua origem nos Estados Unidos da América, que adota o sistema jurídico da common law, baseado mais em precedentes judiciais em detrimento de textos legais, a figura do Land Trust não é reprodutível ao passível de tradução ao português.

Deste modo, prefere-se trabalhar com a tradução de Termo Territorial Coletivo, evocando o aspecto consensual e coletivo do instrumento.

Como visto brevemente no capítulo anterior, as primeiras experiências foram realizadas nos Estados Unidos da América na década de 60, ligadas aos movimentos por direitos civis e localizadas, na sua totalidade, em áreas rurais. No início, o projeto enfrentou a resistência dos moradores e poucos foram efetivamente implantados neste primeiro momento. 0 primeiro TTC urbano penas foi organizado em 1980.

Com o passar do tempo, o modelo dos TTCs foi se aperfeiçoando e a demonstração de resultados começou a vencer as desconfianças iniciais, dando-lhe mais força: em 1995 havia cerca de 100 TTCs nos Estados Unidos da América, enquanto que em 2005 havia mais de 200, com uma estimativa de 12 novos sendo constituídos a cada ano. Atualmente, os TTCs estão em operação em 45 estados e em outros países como Canadá, Inglaterra, Escócia, Austrália e Quênia (DAVIS, 2010, p.210). Muito desta expansão se deve ao fato dos TTCs terem deixado as fronteiras rurais e passado a ter aplicação expressiva nas cidades nas quais, de fato, as situações de vulnerabilidade são múltiplas e graves.

\footnotetext{
${ }^{15}$ Exceção se faz ao programa Produção Social da Moradia (PSM) vinculado ao Fundo Nacional de Habitação de Interesse Social.
} 
A difusão dos TTCs fez com que sua modelagem se tornasse maleável, para que pudesse se adaptar às diversidades locais. Nas palavras de John Davis:

"The CLT has been reinvented repeatedly over the years, adapting to new audiences, conditions, and applications. Such flexibility has been a perennial source of renewal and vigor, helping the CLT to spread far and wide. A deeper appreciation for the model's evolution may encourage today`s practitioners to continue the experimentation that gave rise to the model in the first place" (DAVIS, 2010, p.10)

Os arranjos jurídicos e institucionais dos TTCs de fato passaram a variar conforme a realidade de cada uma das localidades em que se instaura. No entanto, é possível definir algumas características comuns às ações que se colocam sob o título de TTC, que são: (i) terra de propriedade coletiva; (ii) construções/moradias de propriedade individual; (iii) sustentabilidade na manutenção do TTC; (iv) gestão participativa e (v) ingresso voluntário (DAVIS, 2010, p. 26).

A propriedade coletiva da terra é o fundamento básico da segurança da posse proporcionada pelos TTCs. Os arranjos institucionais que garantem esta coletividade via de regra passam pela constituição de uma pessoa jurídica que será a proprietária formal dos terrenos, com participação dos moradores na sua gestão. A propriedade e gestão coletivas dão ao modelo a possibilidade de fazer restrições a possíveis novos moradores da área com o objetivo de manter suas características originárias, por exemplo, apenas permitindo que haja transmissão de imóveis para pessoas de baixa renda.

O que acontece nos TTCs, longe da negação ou disputa do paradigma da propriedade privada, é a busca de um formato de apropriação privada da terra que garanta a segurança da posse dos moradores diante das inúmeras ameaças que se colocam no âmbito da (re)produção constante da cidade no capitalismo, especialmente aquelas relacionadas às sucessivas mudanças nos gradientes de valorização que implicam a expulsão mercadológica dos moradores de localidades que vão se valorizando rumo às sempre renovadas franjas da cidade.

É indispensável, para a aplicação do modelo de TTC, que seja garantida uma gestão participativa por agentes interessados no território. Em uma formulação clássica, esta gestão é feita em um formato tripartite, com a formação de uma espécie de órgão deliberativo colegiado composto por $1 / 3$ de moradores; $1 / 3$ de técnicos indicados pelos moradores e $1 / 3$ de moradores de bairros vizinhos (DAVIS e JACOBUS, 2008, p.314).

Ainda que este formato clássico não seja reprodutível em todos os locais nos quais se pretenda implantar o modelo dos TTCs, é fundamental que a gestão institucional seja feita de forma participativa e que esta participação seja garantida materialmente, em todo o processo de tomada de decisões sobre o território, e não apenas formalmente, com deliberações apenas sobre propostas já construídas.

No Brasil, a implantação de um modelo de Termo Territorial Coletivo em áreas informais já consolidadas passa pela necessária costura das esferas do planejamento urbano e do direito. No âmbito do planejamento urbano, é fundamental a construção de um processo de planejamento tipicamente insurgente (MIRAFTAB, 2009) junto aos moradores. Ou seja, é fundamental engajá-los em um processo de conscientização e definição dos rumos desejados para seu território, conhecendo os limites e possibilidades e definindo estratégias para o alcance dos resultados esperados.

A partir deste processo participativo e insurgente de conscientização e planejamento do território, torna-se necessário pensar em arranjos jurídicos que permitam a realização da estrutura necessária para um TTC.

Uma primeira opção, seguindo inclusive a experiência bem sucedida de Porto Rico, é a edição de uma lei específica sobre o tema, com regulamentação extensiva sobre o tema. Em termos materiais, esta seria a solução ideal, permitindo um desenho jurídico personalizado do instituto, completamente 
adaptado a suas necessidades. Entretanto, dados os trâmites legislativos e as complexidades que envolvem a negociação política, aguardar a edição de uma lei específica prorrogaria indefinidamente qualquer possibilidade de implantação do modelo (ALGOED et al., 2019, p.5).

Sendo assim, buscou-se pensar um arranjo alternativo a partir dos instrumentos já existentes no ordenamento jurídico brasileiro, capaz de fornecer a base para a implementação de um modelo brasileiro de Community Land Trust, a partir das especificidades e necessidades locais.

Quanto à instituição proprietária da terra e gestora do TTC, dentre as diversas formas associativas reconhecidas pelo ordenamento jurídico brasileiro, podemos destacar as associações, fundações e cooperativas.

As duas primeiras são formas de pessoas jurídicas já consolidadas no Brasil e as principais diferenças entre elas são de duas ordens. A primeira se refere à gestão: as associações permitem arranjos de maioria que podem alterar a finalidade inicialmente estabelecida para si e seus bens. Deste modo, acaba padecendo de uma fragilidade que exigirá esforços para sua correção, ao mesmo tempo que é a forma que tem o processo menos burocrático de estabelecimento. A segunda se refere à necessidade de que, para a criação de uma fundação, já exista patrimônio a ser destinado para suas atividades fins. Ou seja, no caso de criação de uma fundação para modelar um TTC, esta fica condicionada à possibilidade de disposição dos imóveis no momento de seu surgimento, não podendo ser feita antes da etapa da regularização fundiária descrita anteriormente (BORBA, 2019, p.209 - 221).

Quanto às cooperativas, sua regulamentação jurídica ainda se revela insuficiente no Brasil, embora seja o instrumento preferencial dos movimentos sociais em sua organização interna. Um dos problemas encontrados para a utilização desta figura jurídica é a necessidade de comprovação de um fim econômico, exigência para a criação de uma cooperativa. Por estar capilarizada entre os movimentos sociais e ser uma alternativa a manutenção e sustentabilidade do TTC, essa opção deve ser considerada.

A utilização de instrumentos e figuras societárias já existentes libera as eventuais iniciativas de aplicação do TTC da necessidade de aguardar ou depender da aprovação de uma legislação específica sobre o tema, o que poderia levar um tempo longo, especialmente considerando o instável cenário político brasileiro.

\section{Potencialidades do Termo Comunitário Territorial para a autogestão habitacional}

A questão da habitação no Brasil tem um histórico de subapreciação por governos e mesmo pela opinião pública. Ao menos desde a metade do século XX - e mesmo algumas décadas antes disso -, momento subsequente ao boom de urbanização promovido pelas políticas de incentivo à industrialização no Brasil, a habitação se mostrou um desafio, especialmente para a população mais pobre.

Durante décadas a "política" habitacional consistiu, fundamentalmente, na omissão do Estado sobre o tema, acompanhada de uma leniência proposital com indispensáveis iniciativas de autoconstrução e mesmo autogestão territorial.

Sob o ponto de vista da população, estes arranjos autogestionários desde a etapa da construção eram mesmo condição de sobrevivência e de garantia da reprodução social, buscando-se as áreas mais próximas de meios de transporte para instalação preferencial (LAGO, 2012, p.5).

Por sua vez, sob o ponto de vista do capitalismo industrial, este tipo de prática se mostrava muito benéfica ao reduzir os custos da cesta de insumos básicos que devem compor o salário dos trabalhadores, que conta com a habitação como um dos elementos principais, indispensável para a reprodução social da força de trabalho. 
A situação de omissão do Estado e predomínio da autogestão construtiva só sofreu alteração considerável com a criação do Banco Nacional de Habitação - BNH, na década de 60 (BONDUKI; KOURY, 2010). Apesar desta iniciativa estatal, o BNH não foi capaz de fazer frente à demanda habitacional, ao mesmo tempo em que recebeu diversas críticas de setores sociais mobilizados em torno da questão habitacional.

Esta mobilização social sobre o tema da habitação cresce em vulto e importância a partir do processo de redemocratização da década de 80 do século XX, incrementando os debates e as buscas por formatos jurídicos e associativos que melhor se adequassem às necessidades dos movimentos $\mathrm{e}$ organizações sociais atuantes no âmbito da moradia, em especial a moradia social (LAGO, 2019, p.6).

Neste cenário se destacam os formatos do associativismo e do cooperativismo, ambos apresentando dificuldades para o objetivo principal de construção de uma política autogestionária de largo espectro, incluindo a já consolidada autogestão construtiva, mas também aspectos mais amplos como a autogestão territorial.

Questões técnicas, associadas com uma deficiência legislativa especialmente no âmbito do cooperativismo, dificultam que as organizações sociais cumpram seus objetivos de garantia de moradia digna e em formato coletivo para seus associados/cooperativados.

Cabe destacar que a legislação principal sobre cooperativismo no Brasil é de 1971, com alterações de 2012, mas que tiveram por objetivo fundamentalmente regulamentar uma modalidade específica de cooperativa que não se adequa à maioria das iniciativas habitacionais (BRASIL, 1971).

Sendo assim, tratam-se de legislação claramente deficiente no sentido de regulamentar diversas atividades com potencial de exercício coletivo e cooperativo, dentre as quais se incluem as iniciativas de autogestão habitacional.

Esta defasagem legislativa se soma a um conservadorismo geral no que se refere ao reconhecimento de arranjos coletivos em diversas esferas. Isto se reflete na extrema dificuldade de obtenção de financiamentos ou titulações coletivas em áreas instituídas a partir de arranjos autogestionários.

Neste cenário, o Termo Territorial Coletivo parece ter muito a contribuir com as iniciativas de autogestão habitacional em sentido amplo, se apresentando como um instrumento com potencial para endereçar, de forma mais adequada que as formas até então utilizadas, as necessidades e peculiaridades dos processos coletivos que caracterizam estas iniciativas.

Ao criar um circuito de utilização de instrumentos e técnicas já existentes em prol de um planejamento e gestão territorial insurgente, que incremente a segurança da posse dos moradores a partir da autogestão territorial, o termo territorial coletivo parece ir ao encontro dos objetivos que vêm sendo perseguidos pelas organizações sociais sobre o tema da habitação.

Seu caráter inovador e sua comprovada eficácia internacional (DAVIS, 2010 p.9) podem habilitá-lo como grande aliado na luta dos movimentos autogestionários de habitação e isto pode se dar de diferentes formas.

Um dos caminhos seria que a proposição legislativa sobre o tema, já abordada anteriormente, trouxesse previsões específicas para que o TTC pudesse englobar as diversas situações de organizações autogestionárias sobre o tema da habitação no Brasil. Assim, por exemplo, poderia ser possível solucionar a questão da formalização de arranjos coletivos de propriedade, bem como consequentes formas coletivas de financiamento - dois dos principais nós enfrentados por organizações autogestionárias na atualidade.

Para além das possibilidades advindas de uma nova legislação, a utilização do instrumento a partir do desenho proposto em formato de circuito oferece novas possibilidades para as organizações 
autogestionárias. Isto porque, ao subverter o caráter individual da propriedade privada sem, no entanto, propor um rompimento com sua institucionalidade, o TTC abre novas possibilidades de titulação e gestão habitacional e do território sob aspectos materiais e formais. Sabe-se que as formas atuais de titulação engessam práticas autogestionárias e a combinação entre propriedade privada individual e coletiva proposta pelo TTC pode representar um avanço para a formalização de tais práticas.

Esta possibilidade de formalização em termos de titulação pode, por consequência, levar à liberação de outro importante nó enfrentado por organizações ligadas à causa da autogestão habitacional, qual seja, o financiamento. Isto porque, uma vez reconhecido um arranjo de titularidade coletiva da terra abre-se uma janela de possibilidades jurídicas de financiamento em formato coletivo, por exemplo possibilidades de financiamento diretamente à pessoa jurídica titular da área, que por sua gestão coletiva passa a ter condições de cotizar os valores entre os participantes.

Para além destas possibilidades formais, a forma de organização na qual se ancora o TTC, envolvendo os moradores não apenas na gestão de uma pessoa jurídica, mas no planejamento e definição de medidas a serem adotadas no próprio território, tende a potencializar os arranjos autogestionários nos seus aspectos mais participativos e emancipatórios ao ampliar os conhecimentos e ações dos moradores sobre seu território (THADEN e LOWE, 2014).

Conforme visto, acredita-se que o TTC tenha potencial para somar, em diversos aspectos, nas lutas travadas pelas organizações autogestionárias que militam no âmbito habitacional. Exemplo disso temos na experiência de Cooper Square ${ }^{16}$, na qual a Associação de Habitação Mútua Cooper Square (MHA) foi constituída como uma organização cooperativa sem fins lucrativos, com o objetivo de administrar habitações de baixa renda (Área de Renovação Urbana) pertencentes à cidade de Nova York. 0 modelo baseado nas habitações coletivas do norte da Europa busca através de uma cooperativa de vários prédios, criar uma economia de escala que dá sustentabilidade às habitações.

A insuficiência até aqui demonstrada pelos instrumentos e legislações nacionais em dar conta das necessidades destas organizações recomendam que se amplie o olhar para outras possibilidades eventualmente aplicadas em outras partes do mundo. É aqui que entra o TTC, como ferramenta com potencial inegável e que demanda maior difusão e estudo para sua adequação e melhor aproveitamento na realidade brasileira.

\section{Conclusão}

A gestão coletiva da propriedade é uma realidade histórica na América Latina, com diversas experiências que se estabeleceram e se fazem presentes até hoje nos mais diversos países. Trata-se de formas alternativas de pensar e exercer a propriedade, para além do paradigma individualista imposto pelo capitalismo, com privilégio de valores coletivos e solidários.

No Brasil, para além das comunidades tradicionais, a gestão coletiva da propriedade ganha força nas últimas décadas a partir das figuras do cooperativismo, da economia solidária, e de iniciativas de produção e reprodução dos meios de vida estruturados na coletivização e na autogestão. Devido ao excesso de burocratização - incentivado pelas previsões legislativas - e à lógica mercadológica de produção dos espaços, tais práticas acabam sendo enfraquecidas e dificultadas, tanto que inexistem regras claras que diferenciem a produção social da habitação por grupos populares cooperativistas e autogestionários da produção realizada por empresas e construtoras na produção habitacional brasileira junto ao governo federal.

0 cooperativismo habitacional autogestionário se baseia em princípios caros à defesa e garantia da segurança da posse e à garantia do direito de moradia de populações vulneráveis uma vez que, além de ser contra-hegemônico, todos os padrões e processos decisórios são construídos

\footnotetext{
${ }^{16}$ Para saber mais acesse: https://coopersquare.org/about-us/our-historical-accomplishments, http://csmha.org/wordpress/ Acesso em: 17/nov/19.
} 
coletivamente, significando e ressignificando conceitos e valores como os de direito à moradia digna, direito à cidade ou mesmo valor de uso. A formatação de um modelo de Termo Territorial Coletivo autogestionário e que se personalize juridicamente na figura da cooperativa, utilizando do instrumental jurídico e político já presente no ordenamento jurídico brasileiro, tem extrema relevância no momento atual. A prática da gestão coletiva do território, dentro de um modelo associativista que busque se distanciar da lógica da propriedade individual típica do sistema capitalista e de racionalidade neoliberal, tem importância pragmática enquanto instrumento garantidor da segurança da posse de populações vulneráveis.

Acredita-se que as possibilidades de um modelo de TTC no suporte de práticas autogestionárias e na criação delas devam ser pautadas na academia e junto a movimentos sociais para maior compreensão e elaboração, tendo em conta, especialmente, seu potencial já demonstrado em diversos países ao redor do mundo de incremento da segurança da posse e de garantia de direitos de populações vulnerabilizadas.

A pesquisa aqui apresentada, embora tenha as limitações inerentes a um estudo teórico, cumpre o objetivo de apresentar um novo mecanismo com o potencial de incrementar a experiência brasileira com as cooperativas habitacionais.

Espera-se, a partir desta perspectiva, que o presente artigo não apenas contribua com um primeiro olhar sobre o tema, despertando o interesse de outros pesquisadores no desenvolvimento da temática, mas seja o pontapé de pesquisas que avaliem modelos autogestionários habitacionais em comunidades vulneráveis, formas de manutenção e sustentabilidade de cooperativas habitacionais instituídas via termos territoriais coletivos, entre outros temas relacionados às formas de garantia de segurança na posse da populações vulneráveis.

\section{Referências}

ALGOED, Line et al. Community Land Trusts and Informal Settlements: Assessing the feasibility of CLT instruments developed by the Caño Martin Peña communities in Puerto Rico for Favelas in Rio de Janeiro. Lincoln Institute of Land Policy Working Paper. Disponível em: https://www.lincolninst.edu/pt-br/publications/articles/community-land-trusts-rios-favelas. Acesso em 02 de out. 2019.

BARAVELLI, José Eduardo. O Cooperativismo Uruguaio na Habitação Social de São Paulo: Das cooperativas FUCVAM à Associação de Moradia Unidos de Vila Nova Cachoeirinha. Dissertação apresentada ao programa de Pós-Graduação da FAU/USP. São Paulo: 2006. Acesso em: http://labhab.fau.usp.br/biblioteca/teses/baravelli_mestrado_cooperativismo.pdf

BORBA, José Edwaldo Tavares. Direito Societário. 17. edição. São Paulo: Atlas, 2019.

BRASIL. Lei n. 5764, de 16 de dezembro de 1971. Disponível em http://www.planalto.gov.br/ccivil_03/LEIS/L5764.htm. Acesso em: 10 de mar. 2020.

CARDOSO, Patrícia. Sistema nacional de habitação de interesse social à luz do novo marco legal urbanístico: subsídios para implementação nos estados e municípios : lei federal no 11.124/05 / [Patrícia Cardoso, Paulo Romeiro]. - São Paulo: Instituto Pólis, 2008. Disponível em: http://www.bibliotecadigital.abong.org.br/bitstream/handle/11465/380/POLIS_sistema_nacional_ha bita\%C3\%A7\%C3\%A3o_interesse_social.pdf?sequence=1\&isAllowed=y

DAVIS, John Emmeus. The Community Land Trust Reader. Massachussets: Lincoln Institute of Land Policy, 2010.

DAVIS e Jacobus, R. The city-CLT partnership: municipal support for community land trusts. Cambridge: Lincoln Institute of Land Policy, 2008. 
GUTTMANN, Robert. Uma introdução ao capitalismo dirigido pelas finanças. Novos Estudos - CEBRAP, São Paulo, n. 82, p. 11-33, nov. 2008.

HARVEY, David. A justiça social e a cidade. São Paulo: Hucitec, 1980.

HARVEY, David. A produção capitalista do espaço. São Paulo: Annablume, 2005.

HARVEY, David. O enigma do capital e as crises do capitalismo. São Paulo: Boitempo, 2011.

HARVEY, David. Os limites do capital. São Paulo: Boitempo, 2015.

KLINK, Jeroen; SOUZA, Marcos Barcellos de. Financeirização: conceitos, experiências e a relevância para o campo do planejamento urbano brasileiro. Cad. Metrop., São Paulo , v. 19, n. 39, p. 379-406, Aug. 2017 . Disponível em http://www.scielo.br/scielo.php?script=sci_arttext\&pid=S223699962017000200379\&lng=en\&nrm=iso. Acesso em 25 de março de 2020.

LAGO, Luciana (org). Autogestão habitacional no Brasil: utopias e contradições. Rio de Janeiro: Letra Capital, 2012

MIRAFTAB, Faranak. Insurgent Planning: Situating Radical Planning in the Global South. In: Planning Theory 8(1), 2009. Disponível em: http://plt.sagepub.com. Acesso em 25 de julho de 2019.

MIRAFTAB, Faranak. Insurgência, planejamento e a perspectiva de um urbanismo humano. In: Revista Brasileira de Estudos Urbanos e Regionais - Recife, v.18, n.3, p.363-377, 2016.

NAHOUM, Benjamín. Algunas claves. Reflexiones sobre aspectos esenciales de la vivienda cooperativa por Ayuda Mutua, Ediciones Trilce, Montevideo, 2013.

KRUPPA, Sonia Maria Portella; GONÇALVES, Alicia Ferreira; MACDONALD, José Brendan. (et alli). Regime Jurídico das Cooperativas Populares e Empreendimentos em Economia Solidária. Série Pensando o Direito, vol. 46. Brasília: Ministério da Justiça, 2012.

RAFFO, Alberto; FRANCO, Jorge. La utopia realizable de la "propriedad colectiva". In.: La vivienda, entre el derecho y la mercancía: las formas de propiedad en ... Regional de Vivienda y Hábitat, WE Effect, Centro Cooperativo Sueco, 2014.

RODRIGUES, Fania. Legado da Revolução Mexicana é base da política de Obrador para campo. 0 vermelho. Disponível em: http://www.vermelho.org.br/noticia/313709-1. Acesso em 20 de novembro de 2018.

THADEN, E e LOWE, J. Residents and community engagement in Community Land Trusts. Cambridge: Lincoln Institute of Land Policy, 2014.

VAINER, Carlos B. Pátria, empresa e mercadoria: notas sobre a estratégia discursiva do planejamento estratégico urbano. In: ARANTES, Otília; VAINER, Carlos; MARICATO, Ermínia. A cidade do pensamento único. Petrópolis: Vozes, 2000. 